\title{
ELECTROCARDIOGRAPHIC SIGNS OF LEFT VENTRICULAR HYPERTROPHY AND STRAIN IN HYPERTENSIVE PATIENTS
}

\author{
BY \\ F. O. SIMPSON* \\ From the Department of Cardiology, Royal Infirmary, Edinburgh
}

Received February 17, 1959

Electrocardiographic abnormalities in hypertensive patients can be divided into two main categories (Smirk, 1957). The first consists of abnormalities that can be directly ascribed to left ventricular "overload" (Sokolow and Lyon, 1949). The second category consists of a miscellaneous group of conditions that are less directly related to left ventricular "overload" and are rather to be considered as complications of vascular disease, such as arrhythmias, conduction defects, and myocardial infarction.

The present study is concerned only with the first category, the intention being to investigate the relationship of the electrocardiographic signs of left ventricular hypertrophy and "strain" to the level of the diastolic blood pressure and to certain other clinical features.

Since the advent of multiple-lead electrocardiography, several studies of the changes in hypertension have been reported. Evans et al. (1945) found some correlation between electrocardiographic changes in bipolar chest leads and the diastolic blood pressure. Leishman (1951) found some correlation with diastolic blood pressure, heart size, and retinal grade, but not between electrocardiographic changes and age, sex, body weight, or angina. Doyle (1953), in an investigation mainly concerned with the improvement obtained in the electrocardiograms of hypertensive patients during treatment with ganglion-blocking drugs, also found some correlation between electrocardiographic changes and diastolic blood pressure taken under basal conditions before treatment was started. Hay (1957) in another follow-up investigation on a series of treated patients (which included Doyle's (1953) group) mentions that the severity of the original cardiographic changes was related to the basal blood pressure and the retinal grade. These investigations have, however, not afforded any clear evidence of why patients with apparently comparable hypertension often have such different degrees of electrocardiographic abnormality. The present study has been made in an attempt to throw further light on this problem. The method of classification of the electrocardiograms used differs from that employed by previous workers and is based on a separate analysis of the incidence of each of three main changes seen in left ventricular hypertrophy and strain, namely high voltage in QRS complexes, $S-T$ segment depression, and $\mathrm{T}$ wave diphasia or inversion.

\section{MATERIAL AND METHOD}

The twelve-lead electrocardiograms of a series of hypertensive patients were studied in relation to their clinical state. These patients were all investigated on account of hypertension as inpatients in one unit of the Royal Infirmary of Edinburgh in the period 1948-1957. As in a previous investigation, concerned mainly with prognosis (Simpson and Gilchrist, 1958), the average diastolic blood pressure at rest in bed in hospital and the lowest diastolic blood pressure

* At present Edward Wilson Memorial Fellow, Baker Medical Research Institute, Alfred Hospital, Melbourne, Australia. 
recorded during sleep after sedation with sodium amylobarbitone were used as estimates of the blood pressure. Patients were excluded from the study if their average diastolic blood pressure at rest in bed fell below $100 \mathrm{~mm}$. Hg. Patients who had significant valvular disease of the heart or thyroid dysfunction or had been taking digitalis were also excluded, as were patients whose electrocardiograms showed any arrhythmia (other than extrasystoles), bundle-branch block, or definite evidence of myocardial infarction. In all, 203 patients ( 88 men, 115 women) were found suitable for inclusion in the series. 80 per cent of the patients were between 40 and 59 years of age. One only was below 20 years of age, and one was over 70 years of age.

In the analysis of the electrocardiograms for evidence of left ventricular hypertrophy and strain, criteria modified from Sokolow and Lyon (1949) and Goldberger (1953) were used.

(1 a) Height of $\mathrm{R}$ wave in $\mathrm{VVL} 13 \mathrm{~mm}$. or more.

(1 b) Height of $R$ wave in V5+depth of $S$ in V1 greater than $35 \mathrm{~mm}$. (See Fig. 1.) (These changes are subsequently referred to as "high voltage").

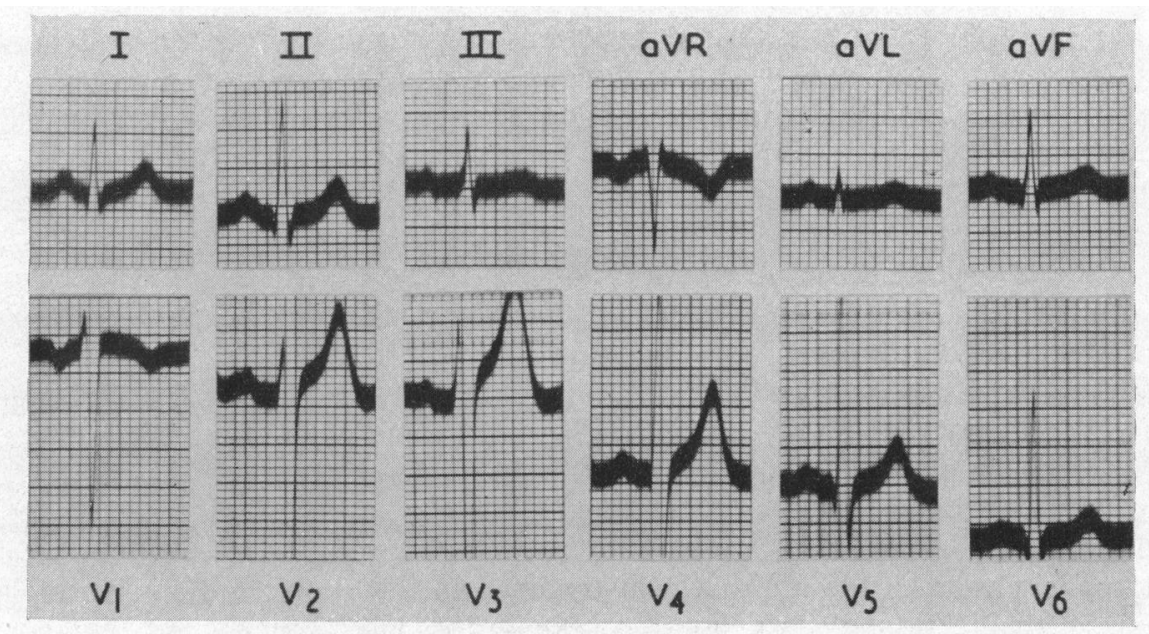

FIG. 1-Electrocardiogram showing the pattern of "high voltage." The height of $\mathrm{R}$ in V5 added to the depth of $\mathrm{S}$ in VI exceeds $35 \mathrm{~mm}$.

(2) Depression of S-T segment of $0.5 \mathrm{~mm}$. or more in leads 1 , aVL (or aVF in vertical hearts), or in V5 and V6. (See Fig. 2.)

(3) Diphasic or asymmetrically inverted $\mathrm{T}$ waves in leads 1 , aVL (or aVF in vertical hearts), or in V5 and V6. (See Fig. 3.) (These changes are subsequently referred to as " $T$ wave changes". Flat or low upright $\mathrm{T}$ waves are not included in this category.)

(4) Peak of R wave in V5 and V6 delayed more than $0.05 \mathrm{sec}$. after the start of the ventricular complex, but not sufficiently to indicate left bundle-branch block.

\section{RESULTS}

Incidence of Abnormalities. Only 10 per cent of the male patients and 17 per cent of the women had normal electrocardiograms. This is a reflection of the severity of the hypertensive vascular disease in this series of patients, and it is probably related to the fact that all patients whose diastolic blood pressure fell below $100 \mathrm{~mm}$. $\mathrm{Hg}$ at rest in bed were excluded from the series.

60 per cent of the men and 56 per cent of the women showed high voltage (Table II), 63 per cent of the men and 57 per cent of the women showed S-T depression, and 74 per cent of the men and 61 per cent of the women showed $\mathrm{T}$ wave changes. All these abnormalities were not 


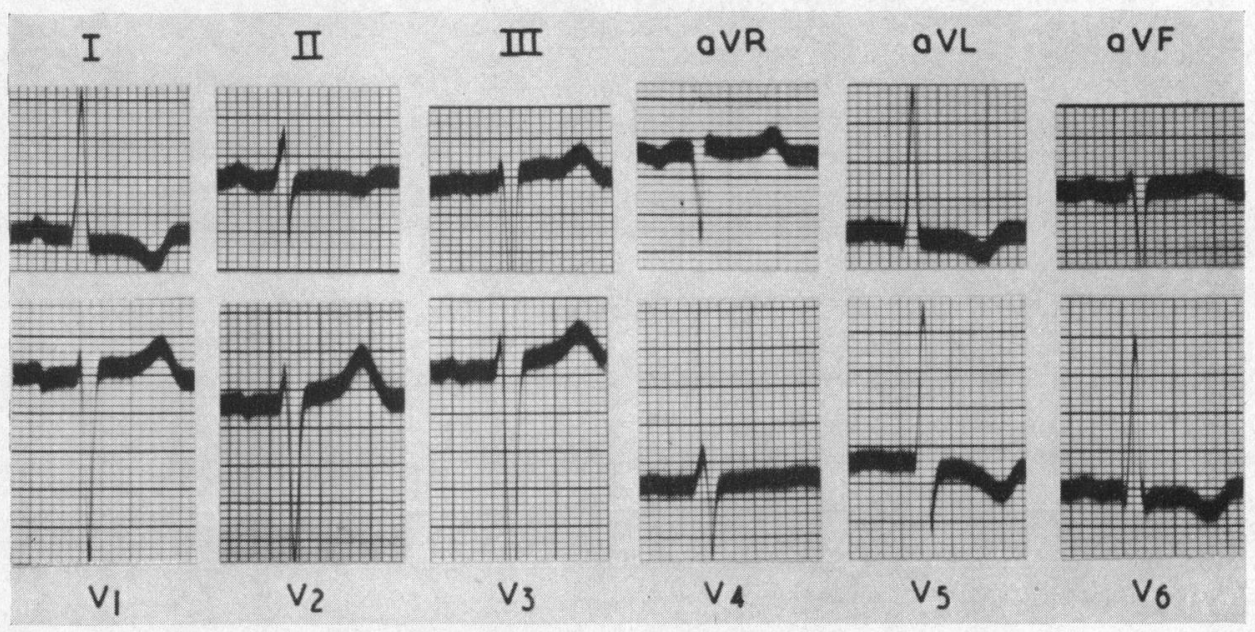

FIG. 2-Electrocardiogram showing depression of $\mathrm{S}-\mathrm{T}$ segment of $0.5 \mathrm{~mm}$. or more in leads I, aVL, V5 and V6. T waves are asymmetrically inverted in these leads. $R$ in aVL exceeds $13 \mathrm{~mm}$., and there is high voltage also in the chest leads.

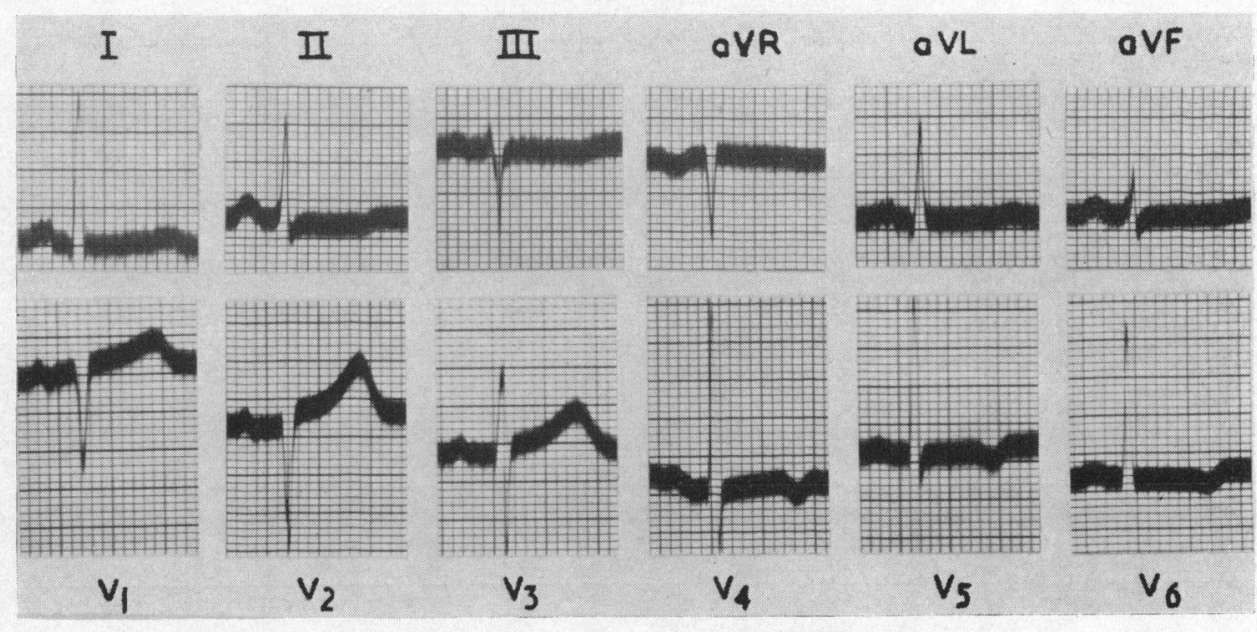

FIG. 3.-Electrocardiogram showing asymmetrically inverted $T$ waves in V4, V5 and V6, without high voltage or $\mathrm{S}-\mathrm{T}$ segment changes.

always present in the same patient (Table I). S-T depression was usually associated with $\mathrm{T}$ wave change, and has therefore been omitted from some parts of the analysis and discussion.

The peak of the R wave in V5 and V6 was delayed more than $0.05 \mathrm{sec}$. after the start of the ventricular complex in only 6 patients.

Relationship of Electrocardiogram to Diastolic Blood Pressure. Subdivision of the patients according to their average diastolic blood pressure at rest in hospital showed that the incidence of each type of electrocardiographic abnormality increased with rise in the diastolic blood pressure (Table II). This relationship was significant at the 1 per cent level for high voltage and $T$ wave changes in the women and for $T$ wave changes in the men; it just failed to be significant at the 5 per cent level for high voltage in the males. 
TABLE I

ANalysis of EleCtrocardiographic ABNormalities

(Figures in brackets are percentages)

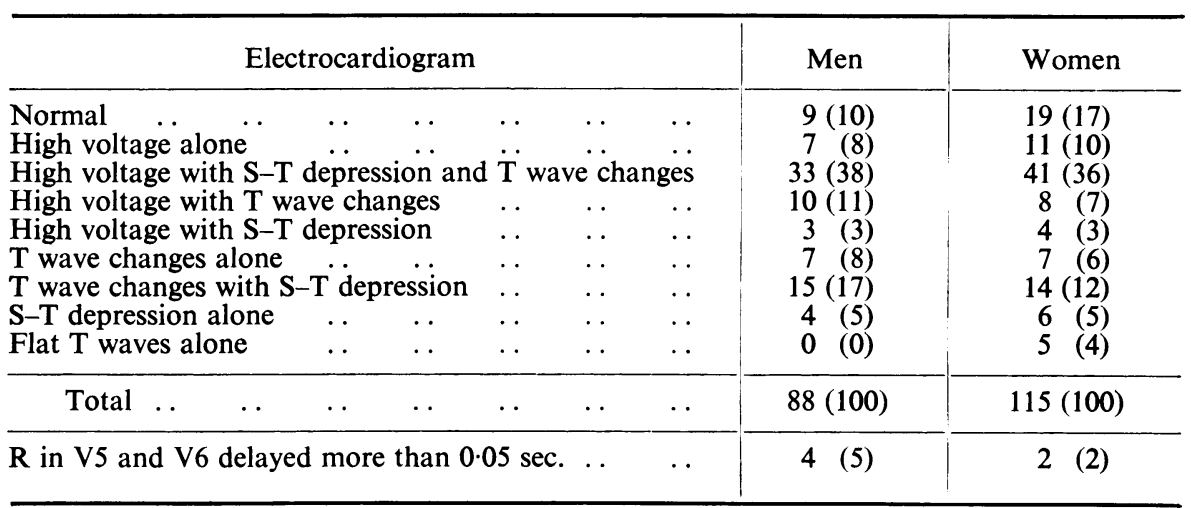

TABLE II

Relationship of Electrocardiographic Abnormalities to Average Level of Diastolic Blood Pressure at Rest in Hospital

A. MEN

(Figures in brackets are percentages)

\begin{tabular}{|c|c|c|c|c|}
\hline $\begin{array}{l}\text { Average resting } \\
\text { diastolic blood } \\
\text { pressure } \\
\mathrm{mm} . \mathrm{Hg}\end{array}$ & $\begin{array}{l}\text { Number of } \\
\text { patients }\end{array}$ & $\begin{array}{c}\text { High } \\
\text { voltage }\end{array}$ & $\begin{array}{c}\mathbf{S}-\mathbf{T} \\
\text { depression }\end{array}$ & $\begin{array}{l}T \text { wave } \\
\text { inversion }\end{array}$ \\
\hline $\begin{array}{c}100-109 \\
110-119 \\
120-129 \\
130-139 \\
140 \text { and over }\end{array}$ & $\begin{array}{l}17 \\
21 \\
20 \\
19 \\
11\end{array}$ & $\begin{array}{r}7(41) \\
12(57) \\
13(65) \\
13(68) \\
8(73)\end{array}$ & $\begin{array}{r}5(29) \\
14(67) \\
14(70) \\
13(68) \\
9(82)\end{array}$ & $\begin{array}{r}8(47) \\
15(71) \\
16(80) \\
16(84) \\
10(91)\end{array}$ \\
\hline \multirow[t]{2}{*}{ Total } & 88 & $53(60)$ & $55(63)$ & $65(74)$ \\
\hline & $\begin{array}{c}\chi^{2} \text { linear trend } \\
\mathrm{p} \text { value }\end{array}$ & $\begin{array}{c}3.64 \\
p=0.056\end{array}$ & & $\begin{array}{c}8.14 \\
\mathrm{p}<0.01\end{array}$ \\
\hline
\end{tabular}

B. WOMEN

\begin{tabular}{c|c|c|c|c}
\hline $\begin{array}{c}\text { Average resting } \\
\text { diastolic blood } \\
\text { pressure } \\
\text { mm. Hg }\end{array}$ & $\begin{array}{c}\text { Number of } \\
\text { patients }\end{array}$ & $\begin{array}{c}\text { High } \\
\text { voltage }\end{array}$ & $\begin{array}{c}\text { S-T } \\
\text { depression }\end{array}$ & $\begin{array}{c}\text { T wave } \\
\text { inversion }\end{array}$ \\
\hline $100-109$ & 23 & $6(26)$ & $9(39)$ & $10(44)$ \\
$110-119$ & 33 & $16(49)$ & $16(49)$ & $18(55)$ \\
$120-129$ & 31 & $16(52)$ & $17(55)$ & $19(61)$ \\
$130-139$ & 14 & $12(86)$ & $11(79)$ & $11(79)$ \\
140 and over & 14 & $14(100)$ & $12(86)$ & $12(86)$ \\
\hline Total & 115 & $64(56)$ & $65(57)$ & $70(61)$ \\
\hline & $\chi^{2}$ linear trend & 23.51 & & $8 \cdot 74$ \\
\hline & p value & $\mathrm{p}<0.01$ & & $\mathrm{p}<0.01$ \\
\hline
\end{tabular}


TABLE III

Relationship of Electrocardiographic Abnormalities to Lowest Level of Diastolic Blood Pressure during SleEp after Amylobarbitone Sedation

A. MEN

(Figures in brackets are percentages)

\begin{tabular}{|c|c|c|c|c|}
\hline $\begin{array}{l}\text { Lowest diastolic } \\
\text { blood pressure } \\
\text { during sleep after } \\
\text { amylobarbitone } \\
\text { sedation } \\
\mathrm{mm} . \mathrm{Hg}\end{array}$ & $\begin{array}{l}\text { Number of } \\
\text { patients }\end{array}$ & $\begin{array}{c}\text { High } \\
\text { voltage }\end{array}$ & $\begin{array}{c}\mathbf{S}-\mathbf{T} \\
\text { depression }\end{array}$ & $\begin{array}{l}\mathrm{T} \text { wave } \\
\text { inversion }\end{array}$ \\
\hline $\begin{array}{c}\text { Below } 90 \\
90-99 \\
100-109 \\
110-119 \\
120 \text { and over }\end{array}$ & $\begin{array}{l}19 \\
21 \\
17 \\
14 \\
17\end{array}$ & $\begin{array}{r}8(42) \\
12(57) \\
10(59) \\
10(71) \\
13(76)\end{array}$ & $\begin{array}{r}6(32) \\
14(67) \\
13(76) \\
8(57) \\
14(82)\end{array}$ & $\begin{array}{r}7(37) \\
15(71) \\
14(82) \\
13(93) \\
16(94)\end{array}$ \\
\hline \multirow[t]{2}{*}{ Total } & 88 & $53(60)$ & $55(63)$ & $65(74)$ \\
\hline & $\begin{array}{l}\chi^{2} \text { linear trend } \\
\mathrm{p} \text { value }\end{array}$ & $\begin{array}{c}5.03 \\
p<0.05\end{array}$ & & \\
\hline
\end{tabular}

B. WOMEN

\begin{tabular}{c|c|c|c|c}
\hline $\begin{array}{c}\text { Lowest diastolic } \\
\text { blood pressure } \\
\text { during sleep after } \\
\text { amylobarbitone } \\
\text { sedation } \\
\text { mm. Hg }\end{array}$ & $\begin{array}{c}\text { Number of } \\
\text { patients }\end{array}$ & $\begin{array}{c}\text { High } \\
\text { voltage }\end{array}$ & $\begin{array}{c}\text { S-T } \\
\text { depression }\end{array}$ & $\begin{array}{c}\text { T wave } \\
\text { inversion }\end{array}$ \\
\hline $\begin{array}{c}\text { Below 90 } \\
90-99\end{array}$ & 33 & $13(40)$ & $18(55)$ & $21(64)$ \\
$100-109$ & 22 & $8(36)$ & $6(27)$ & $9(41)$ \\
$110-119$ & $16(55)$ & $18(62)$ & $17(59)$ \\
120 and over & 16 & $14(93)$ & $10(67)$ & $10(67)$ \\
\hline Total & 115 & $13(81)$ & $13(81)$ & $13(81)$ \\
\hline
\end{tabular}

TABLE IV

Relationship of Electrocardiographic Abnormalities to Age in Patients with Average Resting Diastolic BloOd Pressures between 100-129 mm. Hg

(Figures in brackets are percentages)

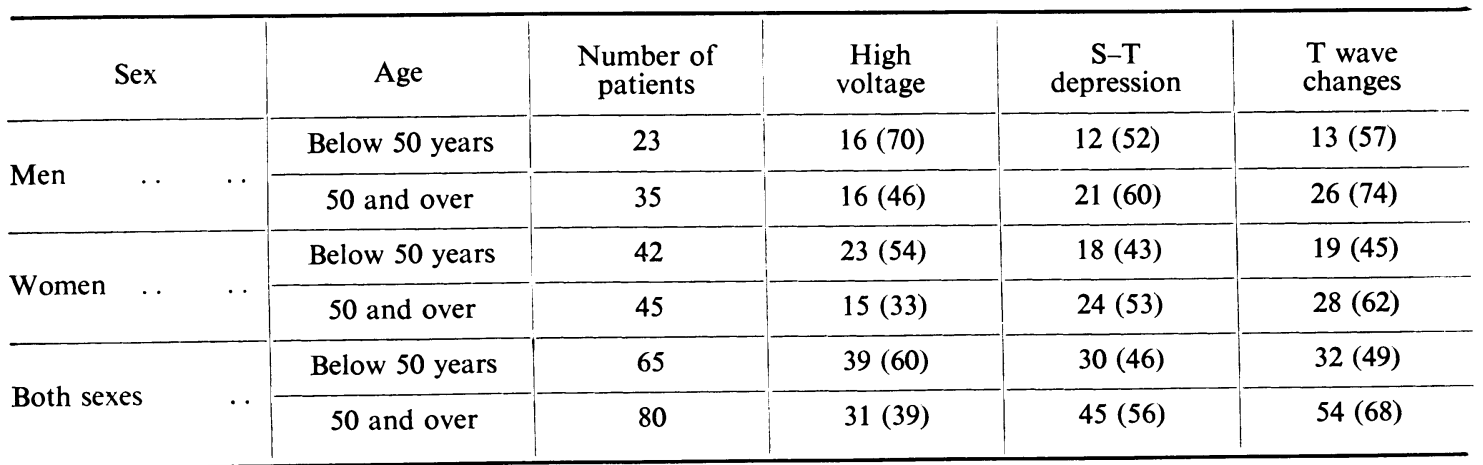


TABLE V

Relationship of Electrocardiographic Abnormalities to Average Resting Diastolic Blood Pressure AND RETINAL GRADE

A. MEN

(Figures in brackets are percentages)

\begin{tabular}{|c|c|c|c|c|c|}
\hline $\begin{array}{l}\text { Average resting } \\
\text { diastolic } \\
\text { blood pressure } \\
\mathrm{mm} . \mathrm{Hg}\end{array}$ & $\begin{array}{l}\text { Retinal } \\
\text { grade }\end{array}$ & $\begin{array}{l}\text { Number of } \\
\text { patients }\end{array}$ & $\begin{array}{l}\text { High } \\
\text { voltage } \\
\text {. }\end{array}$ & $\begin{array}{c}\mathbf{S}-\mathbf{T} \\
\text { depression }\end{array}$ & $\begin{array}{l}T \text { wave } \\
\text { changes }\end{array}$ \\
\hline \multirow{2}{*}{ Between 100-119 } & O-I and II & 26 & $10(39)$ & $8(31)$ & $13(50)$ \\
\hline & III and IV & 12 & $9(75)$ & $11(92)$ & $10(83)$ \\
\hline \multirow{2}{*}{120 and over } & O-I and II & 16 & $11(69)$ & $12(75)$ & $13(81)$ \\
\hline & III and IV & 34 & $23(68)$ & $24(71)$ & $29(85)$ \\
\hline
\end{tabular}

B. WOMEN

\begin{tabular}{|c|c|c|c|c|c|}
\hline $\begin{array}{l}\text { Average resting } \\
\text { diastolic } \\
\text { blood pressure } \\
\mathrm{mm} . \mathrm{Hg}\end{array}$ & $\begin{array}{l}\text { Retinal } \\
\text { grade }\end{array}$ & $\begin{array}{l}\text { Number of } \\
\text { patients }\end{array}$ & $\begin{array}{c}\text { High } \\
\text { voltage }\end{array}$ & $\begin{array}{c}\text { S-T } \\
\text { depression }\end{array}$ & $\begin{array}{l}T \text { wave } \\
\text { changes }\end{array}$ \\
\hline \multirow{2}{*}{ Between 100-119 } & O-I and II & 43 & $15(35)$ & $17(40)$ & $18(42)$ \\
\hline & III and IV & 13 & $7(54)$ & $8(62)$ & $10(77)$ \\
\hline \multirow{2}{*}{120 and over } & O-I and II & 21 & $13(62)$ & $12(57)$ & $12(57)$ \\
\hline & III and IV & 38 & $29(76)$ & $28(74)$ & $30(79)$ \\
\hline
\end{tabular}

However, when the diastolic blood pressure was assessed as the lowest level obtained during sleep after amylobarbitone sedation, the relationship of high voltage to diastolic blood pressure was significant at the 5 per cent level in the men (Table III). In the women, on the other hand, the relationship of electrocardiographic abnormalities to lowest sleeping diastolic blood pressure was much less consistent. This was an unexpected finding, as a previous study (Simpson and Gilchrist, 1958) had shown that the lowest sleeping diastolic blood pressure was a good guide to prognosis and was also closely related to other clinical indications of severity, such as the retinal grade.

These findings indicate a closer relationship between the incidence of electrocardiographic changes and the average level of the resting diastolic blood pressure than has previously been demonstrated. However, it is clear that the severity of the electrocardiographic changes is influenced also by other factors, and it is reasonable to suppose that age, sex, body weight, coronary atheroma and other arterial disease might be of importance. The relationship of the electrocardiographic changes to these factors, and to the cardiac functional state, will now be considered.

Relationship of Electrocardiogram to Age. The age of the patient was found to have a considerable influence on the incidence and type of electrocardiographic changes. In patients with average resting diastolic blood pressure from 100 to $129 \mathrm{~mm}$. $\mathrm{Hg}$ (above this level all three electrocardiographic abnormalities were very common), high voltage was present in 60 per cent of those under the age of 50 years, but in only 39 per cent of those aged 50 years or more (Table IV, $\chi^{2}=5.66$, $p<0.05)$. T wave changes, on the other hand, were present in 49 per cent of those under the age of 50 years, and in 68 per cent of those aged 50 years or more (Table IV, $\chi^{2}=4.23, p<0.05$ ). The 
two sexes were similar in this respect. It is thus evident that $\mathrm{T}$ wave changes become more common as age advances, but the QRS voltage appears not to increase and may possibly even decrease as age adyances. High voltage without $\mathrm{T}$ wave changes was much more common below than above the age of 50 years, while $\mathrm{T}$ wave changes without high voltage were much commoner above this age than below it.

A comparison between the two age groups showed some minor differences in other respects, and these are considered in some detail as they might affect the validity of these findings. Firstly, there were rather fewer patients in the older age group with average diastolic blood pressure between $120 \mathrm{~mm}$. and $129 \mathrm{~mm}$., but there is no apparent reason why this should affect the relative incidence of high voltage and $\mathrm{T}$ wa ve changes to any extent. Secondly, a history of angina of effort was more common in the patients aged 50 years or more, but there was no increase in incidence of $T$ wave changes in such patients in this series (see below). Thirdly, the proportion of hearts with a vertical electrical position, was rather higher in the younger age group, but in the series as a whole the patients with vertical hearts ( 35 in all) did not differ significantly from the remainder in the incidence of high voltage or S-T and T wave changes. Finally, the older patients tended to have more dyspnœa on effort, and in the series as a whole $\mathrm{T}$ wave changes were more common in patients with this symptom (see below). This would only affect the validity of the comparison of the electrocardiogram if the symptom had led to a difference in the selection of patients in the two age groups; it seems unlikely that any such difference occurred.

Relationship of Electrocardiogram to Clinical Coronary Artery Disease. Patients with definite electrocardiographic evidence of myocardial infarction had been excluded from the series, but 21 men and 15 women gave histories of angina of effort. The incidence of high voltage and $\mathrm{T}$ wave changes in these patients was 57 per cent and 76 per cent, respectively for the men, and 33 per cent and 60 per cent respectively for the women-figures not dissimilar to those for the whole series (Table II), apart from the lower incidence of high voltage in the small group of women with coronary artery disease. The level of diastolic blood pressure in these patients with angina was very similar to that in the series as a whole.

It seems reasonable to suppose that if myocardial ischæmia were the cause of the $T$ wave changes of left ventricular strain, then the patients with angina would have shown a particularly high incidence of such changes: this did not occur. The total number of such patients, however, was comparatively small, and no conclusions can be drawn.

Relationship of Electrocardiogram to Retinal Changes. As in a previous study (Simpson and Gilchrist, 1958) there was again found to be quite a close relationship between average diastolic blood pressure and retinal grade (Wagener and Keith, 1939), and between retinal grade and incidence of electrocardiographic abnormalities (Table V). It seems probable that both the incidence of retinal changes and the incidence of electrocardiographic abnormalities are partly dependent on the level of the diastolic blood pressure. However, in patients with average resting diastolic blood pressure below $120 \mathrm{~mm}$. $\mathrm{Hg}$, the group with retinal grades III and IV differed from the group with retinal grades $\mathrm{O}-\mathrm{I}$ and II in having a considerably higher incidence of high voltage $\left(\chi^{2}=4.68\right.$, $\mathrm{p}<0.05)$ and $\mathrm{T}$ wave changes $\left(\chi^{2}=7.74, \mathrm{p}<0.01\right)$ : the patients with retinal grades III and IV tended to be considerably older, only 3 out of 25 being below the age of 50, as compared with 31 out of 72 below the age of 50 in retinal grades $\mathrm{O}-\mathrm{I}$ and II. This difference is significant at the 5 per cent level $\left(\chi^{2}=6 \cdot 56, \mathrm{p}<0.05\right)$.

It seems likely that older patients develop severe retinal changes at lower levels of diastolic blood pressure than do younger patients. It has already been shown in an earlier section that the incidence of $T$ wave changes increases with age; it may therefore be that the high incidence of S-T and $T$ wave abnormalities in patients with severe retinal changes and comparatively low diastolic blood pressure is partly due to their high average age. It is difficult to explain the increased incidence of high voltage on this basis however.

Relationship of Electrocardiogram to Body Weight. No consistent relationship between body weight and electrocardiographic changes could be found, and patients who were 10 per cent or 
more below average weight for their height, sex, and age did not show any significant increase in incidence of high voltage; such an increase might have been expected to occur in view of the finding of Selzer et al. (1958) that marked loss of weight is commonly present when a patient without left ventricular hypertrophy shows high voltage in the electrocardiogram.

Relationship of Electrocardiogram to Cardiac Functional State. No normal electrocardiograms were found in a group of 16 male and 13 female patients who gave a history of paroxysmal nocturnal dyspnœa or who were in congestive heart failure. Eight of these men and 2 of the women were under 50 years of age. The incidence of high voltage and $T$ wave changes was 69 per cent and 100 per cent respectively for the men, and 69 per cent and 69 per cent respectively for the women.

Twenty-five men and 23 women had no abnormal dyspnœa on effort (Cardiac grade I, New York Heart Association, 1947), while 30 men and 63 women had dyspnœa on moderate exertion but no anginal pain (Cardiac grade II). There was little difference in the incidence of high voltage in the two groups, but there was a considerable difference in the incidence of $T$ wave changes in the men with dyspnœa ( 87 per cent) compared with the men without dyspnœa ( 44 per cent). The difference was much less in the women (62 per cent in the patients with dyspncea and 52 per cent in those without dyspnœa). As mentioned above, the patients with dyspnœa tended to be older than those without dyspnœa.

Differences between the Sexes. The differences between the two sexes were on the whole small, in spite of the fact that the men tended to have more severe vascular disease, as far as this could be assessed by their retinal condition. The men, however, did show a slightly higher incidence of $T$ wave changes at all levels of resting diastolic blood pressure (Table IIA). The men also showed a closer relationship between dyspnœa on effort and the incidence of $T$ wave changes.

The women showed a less consistent relationship between the incidence of electrocardiographic abnormalities and the lowest sleeping diastolic blood pressure (Table IIIB). No reason could be found for this. The women showed a particularly close relationship between average resting diastolic blood pressure and the incidence of high voltage (Table IIA).

\section{Discussion AND CONCLUSIONS}

The analysis of this series of patients has shown that the incidence of each of the electrocardiographic changes ascribed to left ventricular "overload" rose with increase in diastolic blood pressure. When the blood pressure was very high, the electrocardiogram usually showed both high voltage and $\mathrm{T}$ wave changes. At lower levels of blood pressure, however, either of these abnormalities was often present alone.

The information that can be gained from the present series concerning the cause of electrocardiographic changes in hypertension is necessarily somewhat limited. It is generally agreed that high voltage is a sign of increase in thickness of the left ventricular wall (although the effect of this is known to be modified by the thickness of the chest wall), and the present findings are in conformity with this. There is less agreement about the cause of the $T$ wave changes, however. These were ascribed by Barnes and Whitten (who apparently were the first to use the term "ventricular strain" in 1929) to a drop in $\mathrm{pH}$ of the fatigued muscle cell. More recently, a relative myocardial ischæmia (Leishman, 1951) and a loss of potassium from the "strained" muscle fibres (Goldberger, 1953) have been invoked as causes of the $T$ wave changes. Such explanations appear to be required only in the case of the so-called "primary T wave changes," that occur in the presence of normal QRS complexes (Goldberger, 1953). T wave changes that occur in the presence of abnormally large and wide QRS complexes are considered to be "secondary" to the QRS changes. The ventricular gradient, which might have been of some assistance in differentiating between "primary" and "secondary" $T$ wave changes, was not calculated in this investigation, but the fact that the peak of the $\mathrm{R}$ wave in the left chest leads was delayed more than 0.05 second in only 6 patients suggests that the $\mathrm{T}$ wave changes were largely of the "primary" variety. The independent variation of the 
incidence of high QRS voltage and T wave changes in different age groups confirms that these two abnormalities are due to some extent to different causes. It seems likely that the "primary" $T$ wave changes are due to a local metabolic disturbance, such as an increased loss of potassium from the muscle cells, and this hypothetical disturbance appeared to occur more readily in the older patients of the present series. It is tempting to ascribe this finding to an increased degree of coronary atheroma in the older age group. However, as mentioned earlier, no confirmation of such a theory was obtained in the group of patients with clinical coronary artery disease (angina of effort), because $T$ wave changes were not more common in these patients than in the remainder of the series. It is of interest that Simonson and Keys (1952) found a tendency to lower voltage in both QRS complexes and $T$ waves in normal middle-aged men as compared with young men, and they were able to exclude obesity as a possible cause of this.

\section{SUMMARY}

The electrocardiograms of a series of 203 hypertensive patients admitted to hospital were examined for evidence of left ventricular hypertrophy and strain, and the results were correlated with certain clinical details, namely diastolic blood pressure, sex, age, retinal grade, body weight, clinical coronary artery disease, and cardiac functional state.

The incidence of electrocardiographic changes was found to be related to the level of the average resting diastolic blood pressure.

$T$ wave abnormalities were rather more common in men than in women, and were much more common in patients over the age of 50 than in patients under 50 years. High voltage, however, was more common in the younger age group.

$T$ wave changes were not more common in patients with angina of effort than in the remainder of the series.

Both high voltage and $\mathrm{S}-\mathrm{T}$ and $\mathrm{T}$ wave changes in the electrocardiogram were more common in patients with severe retinopathy (retinal grades III and IV), even if the average diastolic blood. pressure was below $120 \mathrm{~mm}$. Hg, than in patients with benign hypertension (retinal grades I and II), and a similar blood pressure, but this may be partly due to the fact that the patients in retinal grades III and IV tended to be older.

The significance of these findings is discussed.

I am grateful to Dr. Rae Gilchrist, under whose charge these patients were admitted and investigated, for his advice in the preparation of this paper. I am also grateful to Dr. Leslie of the Department of Statistics, University of Melbourne, for his assistance in the statistical analysis.

\section{REFERENCES}

Barnes, A. R., and Whitten, M. B. (1929). Amer. Heart J., 5, 14.

Doyle, A. E. (1953). Amer. Heart J., 45, 363.

Evans, E., Matthews, M., and White, P. D. (1945). Amer. Heart J., 30, 140.

Goldberger, E. (1953). Unipolar Lead Electrocardiography. Lea \& Febiger, Philadelphia.

Hay, D. R. (1957). Australasian Ann. Med., 6, 311.

Leishman, A. W. D. (1951). Quart. J. Med., 20, 1.

New York Heart Association (1953). Nomenclature and Criteria for Diagnosis of Diseases of the Heart and Blood Vessels. 5th Edition. New York Tuberculosis and Health Association, New York, 80.

Selzer, A., Ebnother, C. L., Packard, P., Stone, A. O., and Quinn, J. E. (1958). Circulation, $17,255$.

Simonson, E., and Keys, A. (1952). Circulation, 6, 749.

Simpson, F. O., and Gilchrist, A. R. (1958). Scot. med. J., 3, 1.

Smirk, F. H. (1957). High Arterial Pressure. Blackwell, Oxford, 93.

Sokolow, M., and Lyon, T. P. (1949). Amer. Heart. J., 37, 161.

Wagener, H. P., and Keith, N. M. (1939). Medicine, 18, 317. 